\title{
EDUCAÇÃO INFANTIL NO PERÍODO MILITAR: NUANCES POLÍTICAS DE SUA IMPLANTAÇÃO NA ESCOLA ESTADUAL JOÃO PINHEIRO (ITUIUTABA, MG, 1964 A 1985)
}

\author{
Carlos Henrique de Carvalho ${ }^{1}$ \\ Ana Emília Cordeiro Souto Ferreira ${ }^{2}$
}

\section{RESUMO}

Este artigo tem por propósito apresentar e discutir a base legal que possibilitou a implantação da educação infantil no Brasil, durante o período de vigência da Ditadura Civil Militar no País (1964 a 1985). Mas para proceder tal estudo examinamos como foi esse processo de instauração da educação infantil na Escola Estadual João Pinheiro, no município de Ituiutaba (MG). Por outro lado, também é nosso objetivo discorrer sobre algumas das práticas pedagógicas desenvolvidas nas primeiras séries dessa modalidade de ensino, procurando situá-las no âmbito do comportamento social já determinado pelo próprio contexto educacional vigente à época, ou seja, configurado a partir das diretrizes política-institucionais instauradas pelo Estado Militar.

Palavras-chave: Educação Infantil. Estado Militar. Instituição Escolar. História da Educação.

\section{CHILDREN EDUCATION IN THE MILITARY PERIOD: POLITICAL ASPECTS OF ITS IMPLEMENTATION IN JOÃO PINHEIRO STATE SCHOOL (ITUIUTABA, MG, 1964 - 1985)}

\begin{abstract}
This article aims at presenting and discussing the legal basis which allowed the establishment of children education in Brazil during the military period (1964 up to 1985). In order to accomplish this study, we had to examine the process of the establishment of children education in João Pinheiro State School within the urban area of Ituiutaba (MG). In addition, it was also our objective to describe some pedagogical practices, developed in the first series in this type of schooling, trying to understand them in line with the social behavior, determined by the educational context in operation at the time, that is, established by the political and institutional norms, delivered by the Military State.

Keywords: Children Education. Military State. School Institutions. History of Education.
\end{abstract}

\section{INTRODUÇÃO}

Em de março de 1964 as tensões políticas atingiram um patamar de extrema gravidade no País, poucas vezes verificado na sua história. Esta pressão política se eleva ainda mais pelo pronunciamento do presidente João Goulart no comício de 13 de março de 1964, na estação da Central do Brasil, no Rio de Janeiro, onde anunciou que tomaria novas medidas para promover uma melhor distribuição de renda no País. Enquanto isso, a conspiração civil-militar aumentava de intensidade e ganhava mais adeptos (empresários brasileiros, estrangeiros, da ala mais conservadora da Igreja Católica, classe média, parte da chamada "grande imprensa"), ou como assevera Dreifuss: "as classes dominantes, sob a liderança do bloco multinacional e associado empreenderam uma campanha ideológica e político-militar em frentes diversas, através de uma série de instituições e organizações de classe, muitas das quais eram parte integrante do sistema político populista" (1981, p. 483). 
Se antes de 1964 não se encontravam bases legais para afastar do poder o presidente eleito como vice de Jânio Quadros em outubro de 1960, agora, cada vez mais próximo essa possibilidade estava prestes de acontecer, principalmente, depois do tom supostamente esquerdista assumido por Goulart, ao propor as "reformas de bases" em 1962. Mas o acirramentos político alcança seu "clímax" depois do comício na Central do Brasil, quando Jango reitera sua disposição para pôr em vigência pontos centrais das "reformas de bases", quais sejam: reforma agrária, reforma urbana, encampação das refinarias de petróleo particulares, possibilidade de desapropriação das propriedades privadas; além da "extensão da legislação trabalhista ao campo, a implementação do Estatuto do trabalhador rural, o direito de voto para os analfabetos" (FERREIRA, 2006, p. 24). Em meio a essa efervescência política o general Castelo Branco comandou a operação que, "uma vez mais, como em 1954, um governo populista foi posto abaixo pelos homens de farda" (SKIDMORE, 1988, p.43).

Os marcos educacionais do regime ditatorial militar, em termos do estabelecimentos de reformas, são 1968 a 1971, pois foi no âmbito deles que ocorreram, respectivamente, a reforma universitária e a de primeiro e segundo graus. Com essas duas ações, os militares redefiniram todo o modelo educacional brasileiro em vigência. A própria LDB 4.024/61, que vigorou a partir de 1961, perde seu efeito com a 5.692/71 que, para alguns autores, é considerada uma nova LDB, devido à sua abrangência. Argumento que a 5.692/71 modifica toda a estrutura do ensino fundamental e médio, interferindo, inclusive em aspectos que a LDB de 1961 não interferiu, como estabelecimento do currículo.

Por outro lado, é importante relembrar que o período de 1964 a 1974 caracterizouse não somente como uma época de consolidação e apogeu do autoritarismo, mas também de realização de reformas institucionais, inclusive no que se refere ao campo da educação. Segundo Germano (2000), por política educacional entendemos o conjunto de medidas tomadas ou formuladas pelo Estado e tudo que se refere ou diz respeito ao aparelho de ensino escolar ou não, consequentemente à escolarização - mediante aspectos constantes na democracia e na liberdade, quando estas eram duramente golpeadas pelo Estado militar, que necessitava de bases e legitimação da adesão de parte dos intelectuais, das camadas médias e das massas populares para proclamação em favor da erradicação da pobreza social; quando, de fato, as suas políticas desejavam era manter ou elevar os índices de pobreza relativa, mesmo no contexto de crescimento da economia em momentos diferenciados.

Diante da intensificação de exploração dos interesses do capital prevalecem sobre o trabalho o discurso em favor da erradicação do analfabetismo, a valorização e a expansão da educação escolar com as reformas ousadas propostas com essa finalidade, quando se mantinham a repressão política, a diminuição de recurso da União, além dos poucos recursos públicos destinados à educação. Nesse cenário — da política educacional —, o Estado cumpriu a sua função em relação ao capital, mas até que ponto o regime cumpriu as funções atribuídas ao Estado capitalista em relação à escolarização e qualificação para o trabalho, do ponto de vista político e ideológico, pois podemos observar que se produzia um discurso de valorização da educação escolar, mas as dificuldades de ordem material encontradas pelo Estado e a escassez de recursos destinados à educação pública - montante substanciosos desses recursos eram empregados em setores vinculados à acumulação de capital. Assim, é estabelecida uma política educacional que se direciona para privatização do ensino, estando esta diretamente ligada ao interesse do Estado Militar, ou seja, em promover a expansão da educação, apesar dos limites de ordem estrutural e material. Contudo, a ampliação do sistema educacional foi articulado tendo em vista manter o 
controle político e ideológico, por meio da repressão de professores e alunos, isto é, foi a primeira medida tomada pelo governo imposto pelo golpe de 1964: repressão a tudo e a todos considerados suspeitos de práticas ou mesmo de ideias subversivas. Cunha e Góes (2002) apresentam que a mera acusação de uma pessoa a um programa educativo ou a um livro tivesse inspiração "comunista" era suficiente para demissão ou apreensão.

Portanto, foi através do controle político e ideológico do ensino, visando à eliminação do exercício da crítica social e política, que se pretendia obter a adesão de seguimentos sociais cada vez mais extensos para o projeto de dominação. Tendo o Estado, na área da educação, uma atuação coerente com a ideologia de segurança nacional, revestindo-se de um anticomunismo exagerado. Foi na esteira desses acontecimentos que a política educacional teve seu desenvolvimento: controle social e ideológico da educação em todos os níveis. Porém o Estado Militar não conseguiu exercer o controle pleno da educação, conforme observa Germano:

A política educacional se desenvolveu em torno dos seguintes eixos: 1) Controle político e ideológico da educação escolar, em todos os níveis. Tal controle político, no entanto, não ocorre de forma linear, porém, é estabelecido conforme a correlação de forças existentes nas diferentes conjunturas históricas da época. Em decorrência, o Estado Militar e ditatorial não consegue exercer o controle total e completo da educação. A perda de controle acontece, sobretudo, em conjunturas em que as forças oposicionistas conseguem ampliar o seu espaço de atuação política. Daí os elementos de "restauração" e de "renovação" contidos nas reformas educacionais; a passagem da centralização das decisões e do planejamento, com base no saber da tecnocracia, aos apelos "participacionistas" das classes subalternas. 2) Estabelecimento de uma relação direta e imediata, segundo a "teoria do capital humano", entre educação e produção capitalista e que aparece de forma mais evidente na reforma do ensino de $2^{\circ}$ grau, através da pretensa profissionalização. 3) Incentivo à pesquisa vinculada à cumulação de capital. 4) Descomprometimento com o financiamento da educação pública e gratuita, negando, na prática, o discurso de valorização da educação escolar e concorrendo decisivamente para a corrupção e privatização do ensino, transformando em negócio rendoso e subsidiado pelo Estado. Dessa forma, o Regime incentiva a participação do setor privado na expansão do sistema educacional e desqualifica a escola pública de $1^{\circ} \mathrm{e}$ $2^{\circ}$ graus, sobretudo. (2000, p. 105-6).

Novos mecanismos foram desencadeados: a repressão se abateu sobre os intelectuais comprometidos com as reformas, e o Estado foi buscar meios de criar novos quadros, a aliança com agência USAID (United States Agency for International Development). Os acordos MEC-USAID cobriram um amplo espectro da educação nacional, isto é, o ensino primário, médio e superior. Nessa perspectiva, detectamos que os convênios realizados entre os órgãos se fizeram necessários para adequar o sistema ao modelo econômico brasileiro. Uma série de convênios foi realizada para que fossem resolvidos os problemas direcionados à educação e assim, promover o desenvolvimento e a modernização do País. Nessa perspectiva, Freitas e Biccas esclarecem:

No período de 1964 a 1968 foram assinados 12 acordos com o objetivo de produzir diagnósticos na perspectiva de resolver os problemas educacionais brasileiros. Muitos brasileiros, especialmente os setores mais enriquecidos, encontravam no campo de interlocução aberto com os norte-americanos encaminhamentos para a solução de questões candentes, todas elas 
apresentadas sempre como demandas necessárias para que o Brasil lograsse alcançar desenvolvimento e modernização (2008, p. 268).

Nesse sentido, o governo passa a exercer o papel de acumulador de capital para que se realize a expansão econômica, consequentemente, todo o período vai se caracterizar pelo aumento da oferta do ensino que, embora grande, teve de ser controlado e dentro de alguns limites fixados pelo Estado Militar, para não comprometer a política de desenvolvimento adotada.

\section{A EDUCAÇÃO INFANTIL NO ESTADO MILITAR}

Dentro desse contexto surgem iniciativos as propostas para a educação infantil no Brasil, mas tais iniciativos estiveram subordinadas aos interesses políticos, sociais e econômicos, mesmo depois da criação de alguns programas emergenciais de massa (de baixo custo), muitas vezes desenvolvidos por pessoas da própria comunidade. As creches apareciam como resultado, como símbolo concreto dessas lutas: movimento popular e as reivindicações das mulheres. Diante dessa situação, Oliveira nos esclarece a respeito dos planos desenvolvidos durante este período:

[...] O Plano de Assistência ao Pré-escolar, proposto em 1967 pelo Departamento Nacional da Criança sob a influência do Fundo das Nações Unidas para a Infância e Adolescência - Unicef, organismo internacional de assistência no campo da saúde e nutrição que passava a atuar também na área de educação infantil. (OLIVEIRA, 2005, p. 107).

Dentro desse contexto, muitas entidades adotaram os princípios do tecnicismo e, assim, esboçaram uma orientação mais técnica em seu trabalho com as crianças. Mas, por outro lado, é possível observar também elementos de cunho assistenciais, pois se considerar que o tema da educação infantil está caracterizada apenas como forma alternativa, ou seja, oposta àquela de que guarda cuidados médico-higienista e de assistência. Essa interpretação invalida a ideia de que tais instituições precisariam deixar de ser assistenciais para se transformarem em educacionais. Sobre isso Kuhlmann salienta:

As interpretações precisam superar as simplificações para que de fato levem a conclusões conseqüentes. Sabe-se que foi apenas com expansão da força de trabalho feminina aos setores médios da sociedade, em todo o mundo ocidental, a partir da década de 1960, que se ampliou o reconhecimento das instituições de educação infantil como passíveis de fornecer uma boa educação para as crianças que as frequientassem. A demanda desses setores promoveu uma recaracterização das instituições, que passaram a ser vistas como apropriadas à criança de todas as classes sociais. Mas esse dado real não concentra o âmago dos significados relacionados à expansão da educação infantil. A vontade de propiciar uma boa educação para seus filhos não é exclusiva das mulheres de classe média ou alta. (1998, p. 199).

Esses fatores sociais, remetem-nos a um universo de que a criança ainda permanece em um campo desconhecido, o qual necessita ser desvendado, pois norteia em sua história a uma busca da construção de sua identidade, ou seja, a função educativa dessas instituições. Kuhlmann nos diz que: 
Talvez seja possível explicar as questões analisadas acima [...] pela trajetória histórica da educação infantil em nosso país, na busca da construção de sua identidade. Nesse processo, o trabalho com a criança pequena, que na sua origem voltava-se apenas para assistência, vai, num movimento dialético, entremeado por conflitos, idas e vindas, buscando sua função educativa. Assim, tentando construir um espaço próprio, encontra no modelo escolar a forma privilegiada de sua legitimação, o que acaba por constituir um paradoxo. Entretanto, como não há linearidade nessa caminhada, a busca de identidade própria é constantemente retomada. (1998, p. 200-201).

Pensar a educação das crianças que se encontram nas creches e pré-escolas é pensar uma fase em que se vivenciam as primeiras experiências escolares, concomitantemente às primeiras expressões sexuais, afetivas, emocionais, relacionais extrafamiliares. Tal fato exige uma prática pedagógica interdisciplinar, concebendo a criança como um ser que pertence a um contexto socioeconômico-cultural, possuidora de uma objetividade e subjetividade. E, para o ensino de primeiro grau, além da formação geral, passa a proporcionar a sondagem vocacional e a iniciação para o trabalho.

Germano salienta que: "com isso, o ciclo de reforma da educação brasileira se estende também para o ensino primário e médio, cujo marco principal é a Lei 5.692/71, que fixam diretrizes e bases para o ensino de $1^{\circ}$ e $2^{\circ}$ graus" $(2000$, p. 159). Dentro do contexto educacional, segundo a Lei n. 5.692, de 11 de agosto de 1971, fixou as diretrizes e bases da escola de $1^{\circ}$ e $2^{\circ}$ graus. Na realidade, a intenção do governo militar com a Lei 5.692/71 era estabelecer "uma escola única de $1^{\circ}$ e $2^{\circ}$ graus deveria unificar todo o sistema de ensino, assegurando a um só tempo a continuidade dos estudos e a terminalidade em ambos os gruas" (SOUZA, 2008, p. 268).

Mas ainda de acordo com a Lei 5.692/71, o ensino de $1^{\circ}$ grau compreendendo a duração de oito anos letivos (art. 18) destinava-se à formação da criança e do préadolescente (art. 17), correspondendo ao ensino primário obrigatório e gratuito dos 7 aos 14 anos estabelecido pela Constituição Federal de 1967 (art. 176, § 3º, II). Nesse horizonte observa Souza:

[...] A criação do ensino de $1^{\circ}$ grau em 1971 , pela integração do primário e ginásio, consagrou a extensão da escolaridade obrigatória no País. A implantação do $1^{\circ}$ grau, destinado à formação da criança e do préadolescente, deu-se a partir da eliminação dos exames de admissão e da ampliação (indiscriminada) das séries nos grupos escolares, aproveitando a rede física instalada e ajustando a estrutura administrativa e pedagógica. Uma nova nomenclatura se impôs com a eliminação de denominações usuais na época, como escola isolada, ginásio e equivalentes. (2004, p. 152).

Tais propostas visavam à estimulação precoce e ao preparo para a alfabetização, mantendo, no entanto, as práticas educativas geradas por uma visão assistencialista de educação e de ensino; portanto, o resultado desse processo foi de consequências danosas para a educação infantil. A partir dessa contestação, Kuhlmann caracteriza essa situação dentro das condições de oferta oferecidas pelo Estado Militar, pois, segundo ele:

A perspectiva de oferta de uma educação infantil de qualidade passa a ser considerada uma tendência elitista diante da falta de recursos, os programas de emergência adentram o sistema educacional. Renova-se a também secular proposta da "assistência científica", que isola as crianças pobres em instituições conformadas por uma "pedagogia da submissão", 
que considera que elas não precisam de tudo aquilo que se diz quando se fala na educação das "outras" crianças, que (re)produz as desigualdades sociais (de classe, de raça, de gênero, de geração). Ao mesmo tempo, repõe-se como novidade a relação da educação infantil com um melhor desempenho na escola obrigatória, agora não mais por ela favorecer o desenvolvimento integral da criança, mas por compensar carências da população pobre. Até mesmo quando se manifesta a intenção de garantir o contato com o conhecimento, surgem idéias de que a recreação infantil se oporia ao "pedagógico" por deixar a criança sem contato com a língua escrita. Transfere-se para uma educação pré-escolar de baixa qualidade a solução dos problemas da escola primária - agora ensino de $1^{\circ}$ grau, marcado pelo peso curricular do antigo ginásio, mas que não consegue garantir a conclusão sequer da $2^{\mathrm{a}}$ série, para muitas crianças. (2003, p. 490).

Antes de defender a educação pré-escolar como solução à repetência, é preciso, primeiro, constatar que não são todas as pré-escolas que influenciam a promoção da primeira série. Na maioria das vezes, a prática de iniciar a leitura e a escrita no jardim de infância "roubou" da criança o prazer e os benefícios da atividade lúdica, deixando-a sem a condição de desfrutar da sua infância, ao desenvolver uma a ação pedagógica racionalizada para a educação infantil. Transfere-se para uma educação pré-escolar de baixa qualidade a solução dos problemas da escola primária. Estas mudanças se estabelecem entre as práticas desenvolvidas pelas instituições escolares que desempenham ações relativas à educação, favorecendo um conhecimento elementar precário, não oportunizando às crianças um amadurecimento de seu cognitivo. Portanto, este trabalho assumiu, então, caráter pedagógico, voltado para atividades de maior sistematização, ou seja, a reposição de um melhor desempenho na escola obrigatória em relação à educação infantil. Importante destacar os dados oficiais do Ministério da Educação (no quadro I).

QUADRO I

Dados oficiais do Ministério da Educação .

\begin{tabular}{|c|c|c|c|}
\hline ANO & $\begin{array}{c}\text { MATRíCULAS } \\
\text { NA } \\
\text { PRÉ-ESCOLA }\end{array}$ & $\begin{array}{c}\text { SOMATÓRIO DAS MATRÍCULAS DE CRECHES } \\
\text { MAIS SALAS ALFABETIZADORAS }\end{array}$ & $\begin{array}{c}\text { DISPÊNDIO DO } \\
\text { GOVERNO FEDERAL }\end{array}$ \\
\hline 1967 & - & - & $11,8 \%$ \\
\hline 1972 & 460.000 & - & - \\
\hline 1973 & - & - & $5,5 \%$ \\
\hline 1974 & - & - & $5,2 \%$ \\
\hline 1976 & - & - & $7 \%$ \\
\hline 1984 & $\sim 2.500 .000$ & - & - \\
\hline
\end{tabular}

FONTE: LOPES; FARIA FILHO; VEIGA, 2003, p. 491-92.

Os números acima contrariam preceitos consagrados pela Constituição de 1946, pois conforme Kuhlmann Jr

A partir de 1968, há um acentuado declínio do dispêndio do Governo Federal com a educação. [...] A Constituição da Ditadura Militar de 1967 extinguiu os preceitos de 1946, que previam a aplicação de nunca menos de $10 \%$ de renda resultante dos impostos na manutenção e desenvolvimento do ensino pela União. (2003, p. 492).

Em suma, este projeto visava proporcionar complementação alimentar, evitando os danos da desnutrição e oferecendo estímulos fundamentais para o bom desenvolvimento da 
criança, tanto emocional como cognitivo. As creches eram destinadas aos filhos das camadas populares e as atividades dessas instituições estavam diretamente ligadas à assistência à saúde, sem um programa coeso de educação escolar. Já a pré-escola destinava-se a uma classe social de poder aquisitivo mais elevado, com objetivo de educar as crianças menores de seis anos.

Esses números também sugerem um investimento efetivo na área. É importante destacar que esse processo ocorre concomitante com outros elementos que destacam uma clara ausência de compromisso com a questão dos direitos sociais e da diminuição da pobreza. Frente aos imperativos da Constituição de 1967, Germano nos esclarece:

\begin{abstract}
A Constituição de 1967, que assegurou amplos direitos ao capital, foi bastante restritiva com relação ao trabalho. Assim, a regulamentação dos salários e do mercado de trabalho ficaram afetas ao Executivo, que proibia greves nos serviços públicos e nas atividades essenciais, quebrava a estabilidade no emprego ao incorporar o mecanismo do Fundo de Garantia por Tempo de Serviço (FGTS) à Constituição, e estimulava o trabalho infantil ao reduzir a idade legal mínima de trabalho para doze anos. As conseqüências sociais e econômicas disto são conhecidas: achatamento salarial no que diz respeito à força de trabalho adulta; redução da infância para as crianças trabalhadoras, que ficavam expostas à exploração capitalista mais cedo. Em decorrência, isto significava mais dificuldade ou mesmo impossibilidade de frequiência à escola de um numeroso contingente de crianças. Isso representava, sobretudo, a oferta de uma força de trabalho ainda mais barata, porquanto o menor recebe um salário mínimo inferior ao adulto. (2000, p. 63-4).
\end{abstract}

A Constituição de 1967, que determinava que as crianças adentrassem, cada vez mais cedo, no mundo dos adultos, pode-se detectar que as mesmas estavam, nesse período, expostas ao mercado capitalista. Como consequência, não obtinham os mesmos direitos nem a mesma remuneração dos outros trabalhadores, pois durante este período a educação infantil era colocada num plano secundário para as camadas mais humildes da sociedade. Que desde cedo encaminhavam as crianças para o mercado de trabalho, no sentido de auxiliarem no sustento da família. Cunha e Góes destacam que:

Da constituição de 1967, que o regime autoritário fez o Congresso aprovar, foi retirada a vinculação automática de verbas para o ensino, no plano da União: podia-se gastar $10 \%$, como $15 \%$, como $5 \%$. Assim, a participação do mec no orçamento da União, que oscilou entre $8,5 \%$ e $10,6 \%$, no período 1960-1965, desabou para a metade desses níveis nos anos 70, chegando a 4,3\% em 1975. (2002, p. 50).

Contudo, o descaso do Estado para com a educação, agravado com a ditadura militar, fez com que o Brasil se convertesse num dos países que menos canalizassem recursos para esse setor. As consequências para o sistema educacional e a sociedade brasileira, como um todo, são o sucateamento das escolas, a desvalorização profissional, propiciando má formação, exclusão de muitas crianças do sistema, entre outros efeitos. Os recursos para o sistema educacional não foram recuperados, tornando-se uma "dívidainterna" do país, onde os maiores prejudicados é a grande maioria da população brasileira.

Fruto do processo de abertura política, iniciado a partir de 1977, a população brasileira começou, então, a reivindicar creches como direito do trabalhador e dever do Estado; em função disso houve ampliação de convênios entre governos municipais, 
estaduais e federal. Surgiram creches comunitárias, desvinculadas do apoio governamental, mantidas por empresas industriais, comerciais e órgãos públicos para os filhos de seus trabalhadores; ou, ainda, as funcionárias recebiam ajuda de custo de algumas empresas para pagar creches particulares de sua livre escolha, para atendimento das crianças.

Nesse mesmo período, os parques infantis e outras modalidades de instituições educativas públicas foram abandonando a educação informal das crianças em idade de escolarização regular básica e abrindo suas vagas apenas para o atendimento daquelas em idade pré-escolar. Expandiram-se as escolas municipais de educação infantil, que abrangiam o trabalho anteriormente feito em parques infantis e jardins de infância, e também as classes pré-primárias nas escolas de ensino fundamental. Em relação ao trabalho pedagógico, no início da década de 80, muitos questionamentos eram feitos pelos técnicos e professores acerca dos programas de cunho compensatório e da abordagem da privação cultural na pré-escola. Acumulavam-se evidências de que as crianças das classes populares não estavam sendo efetivamente beneficiadas por esses programas. Ao contrário, eles estavam servindo apenas para uma discriminação e marginalização mais precoce delas. As programações pedagógicas estabelecidas definiam freqüentemente as crianças por suas carências ou dificuldades com o padrão das camadas médias exigido nas escolas vocabulário diferente, dificuldades de comunicação, má condição física, dificuldades de controle e orientação espacial e de discriminação visual e auditiva, auto-imagem negativa, desatenção, dificuldade de relacionamento, apatia e irritabilidade. Contudo, as pré-escolas continuaram limitadas a práticas recreativas e assistenciais em virtude da falta de oportunidades reais para seus professores absorverem as programações propostas. (oliveira, 2005, p. 114-15).

Porém, evidenciaram-se a discriminação e marginalização das crianças, em comparação com o padrão das camadas médias. Ressaltaram-se a limitação das práticas recreativas e assistenciais devido à falta de oportunidade aos professores de programações propostas. Dessas práticas, resultou a expansão das escolas municipais de educação infantil e classes pré-primárias no ensino fundamental. Neste contexto, as associações de bairro, os sindicatos e grupos feministas, os movimentos sociais e grupos políticos de oposição à ditadura militar, as mulheres nos congressos (aquelas que ocupam cargos políticos), os profissionais de órgãos públicos que solidarizam com os anseios populares, ocorridas no período que antecedeu a elaboração da Constituição de 1988, como pressão sobre o poder público, da luta pela democratização pela escola pública, possibilitaram a conquista do reconhecimento da educação em creches e pré-escolas como um direito da criança e um dever do Estado a ser incorporado aos sistemas de ensino.

\section{A IMPLANTAÇÃO DA EDUCAÇÃO INFALTIL NA ESCOLA ESTADUAL JOÃO PINHEIRO DURANTE O ESTADO MILITAR.}

O relevo que a educação infantil ganhou no período militar, no âmbito da Escola Estadual João Pinheiro de Ituiutaba ${ }^{3}$, pode ser aferido pela análise do quadro de matrículas efetivadas entre de 1966 a 1985. Tais números são bastante significativos para que possamos compreender como que se processou a ampliação do atendimento às criação na pré-escola, bem como a frequência dos alunos que estavam matriculados no período 
delimitado acima. Ressaltamos que o número de matrículas informado se refere apenas à pré-escola e a séries iniciais que se faziam presentes no interior de tal instituição nos anos de 1966 a 1984, pois a partir do ano 1984 a escola teve sua extensão de série do ensino fundamental, que até então era apenas de pré-escola a $4^{\mathrm{a}}$ série, e passou a ministrar o ensino de $5^{\mathrm{a}}$ a $8^{\mathrm{a}}$ série. Também ressaltamos que só a partir dos anos de 1970 é que encontramos algumas matrículas dos alunos da pré-escola, pois anteriormente a essa data tal modalidade não se fazia presente na instituição. Portanto, matrícula e vagas são uma questão específica que precisa ser entendida conforme as características da época. Acreditamos que na Escola Estadual João Pinheiro eram matriculadas todas as crianças cuja família buscava uma vaga para permanência delas no contexto educacional de uma escola pública bem conceituada na comunidade local.

QUADRO II

Matrícula realizada de 1966 a 1988.

\begin{tabular}{|cc|}
\hline \multicolumn{2}{|c|}{ ALUNOS DA ESCOLA } \\
\hline Ano & Matrícula \\
\hline 1966 & 834 \\
\hline 1967 & 1.134 \\
\hline 1968 & 1.234 \\
\hline 1969 & 931 \\
\hline 1970 & 830 \\
\hline 1971 & 1.134 \\
\hline 1972 & 855 \\
\hline 1973 & 1.012 \\
\hline 1974 & 1.045 \\
\hline 1975 & 1.094 \\
\hline 1976 & 1.068 \\
\hline 1978 & 1.060 \\
\hline 1979 & 1.163 \\
\hline 1980 & 1.058 \\
\hline 1981 & 1.096 \\
\hline 1982 & 1.199 \\
\hline 1983 & 1.195 \\
\hline 1984 & 1.055 \\
\hline 1985 & 1.038 \\
\hline \hline
\end{tabular}

FONTE: ESCOLA ESTADUAL Jõ̃o PINHEIRO.

Percebemos que a Escola Estadual João Pinheiro tinha um número de matrículas bastante elevado, pois ao fazermos o levantamento do quantitativo de alunos o único recurso a que podíamos recorrer eram os diários dos professores e algumas matrículas. Portanto, verificamos que todas as salas de aulas eram compostas de 35 a 52 alunos, inclusive as salas da pré-escola - estas compostas entre 30 e 42 crianças de ambos os sexos. Nos últimos anos, percebemos que o índice de alunos de séries iniciais teve um leve declínio, pois as salas de aula foram também compostas por alunas de $5^{\mathrm{a}}$ a $8^{\mathrm{a}}$ série. Diante de tais constatações, podemos então chegar à conclusão de que essa escola estadual tinha um número de matrículas elevado.

Mas é necessário considerar, pelas análises realizadas, que a escola tinha um quantitativo de sala de aula composto de sete a dez turmas de todas as séries, portanto as salas da pré-escola eram geralmente constituídas por duas salas de aula. Segundo depoimentos, isso acarretava nessas turmas, no início do ano, uma procura significativa pela comunidade. Ressaltamos que no ano de 1970 houve a formação de apenas duas salas 
de $1^{\text {a }}$ série; as demais séries permaneceram constituídas entre seis e sete turmas. Neste período houve mudanças na estrutura administrativa que afetaram levemente a matrícula da escola. Mas constatamos que estas nos anos subsequentes transcorriam normalmente. Somente em 1984, conforme foi apresentado anteriormente, algumas destas salas foram absorvidas pela extensão de $5^{a}$ série, mas neste contexto Ituiutaba já era constituída por demais escolas que atendiam as crianças, conforme podemos verificar com a criação das escolas da rede pública do contexto ituiutabano. Os alunos que frequentavam a escola segundo fichas de matrículas geograficamente provinham do centro da cidade, mas também se faziam presentes poucos alunos de bairros afastados da parte central.

Dessa forma, ao ter em seu nível de ensino as séries iniciais e com todas as dificuldades vindas de todos os segmentos, tanto econômico como os de estrutura física, o número de crianças que frequentavam as escolas durante esse período era ainda considerado pequeno, pois, se atentarmos para o fato de que na época a maioria da população ativa da nação ganhava um salário mínimo - o que não era suficiente para a simples sobrevivência da parte não ativa adulta - então era por causa do desemprego e constituía um contingente superior à população ativa, que a economia de subsistência geradora de um estado de pobreza crônico ocupava a maior parte do território nacional.

O a educação infantil na Escola Estadual João Pinheiro (à época ainda denominado de Grupo Escolar João Pinheiro) foi sendo divulgado para a cidade e região. Conforme consta nas fontes analisadas - diários de classe —, no ano de 1966 a escola recebeu um número de matrículas significativo: a escola contava com 834 alunos de ambos os sexos. Nas primeiras séries, por determinação da Secretaria de Estado da Educação e pelo departamento de inspeção e assistência técnica de Minas Gerais do dia 17 de fevereiro de 1968.

A fim de diminuir dúvidas, tendo em vista o cumprimento do art. 168, § II da Lei de Diretrizes e Bases da Educação Nacional e do art. 97 do código do ensino primário, esclarecemos:

1.1 O Ensino Primário oficial e gratuito para todos: o ensino oficial ulterior ao primário sê-lo-á para quantos provarem falta ou insuficiência de recursos. 1.2 O Ensino Primário Elementar é obrigatório e gratuito para todos os menores em idade escolar. 1.3 Não deve ser cobrada, portanto, sob qualquer pretexto, nenhuma taxa de matrícula aos candidatos a qualquer série dos cursos pré-primário, primário elementar, primário complementar e primário supletivo dos estabelecimentos oficiais de ensino do Estado, o procedimento da matrícula obedecerá ao disposto na Portaria 70/68 de $11 / 1 / 68$.

II - A secretaria de Estado da Educação não exigiu, nem distribuiu exemplares de provas de seleção para ingresso aos estabelecimentos oficiais de ensino das categorias acima mencionadas. (GRUPO ESCOLAR JOÃO PINHEIRO, s. d, s. p.).

Conforme portaria 65/69, o secretário de Estado da Educação de Minas Gerais considera o disposto na lei 5.213, de 2 de julho de 1969, regulamentada pela portaria 57/69; a referida lei 5.213 estabelece normas para fixação de dias letivos do ano escolar no atual sistema de educação:

- as citadas normas estão explicitas na Resolução 96/68, do Conselho Estadual de Educação que fixa em 200 o número de dias letivos;

- a Lei 5.213, tendo vigência a partir da data da publicação, 3 de julho de 1969 , atinge apenas o $2^{\circ}$ semestre letivo; 
- o ano letivo de 1969 encerrar-se-á no dia 10 de dezembro, ficando, assim, revogada a Portaria 57/69, de 3 de outubro de 1969. (MINAS GERAIS, 1969).

Nessa perspectiva, a sociedade tijucana, através de participação dos pais das crianças da cidade, exigia a concretização para que esses e outros assuntos referentes à infância se tornassem essenciais ao reconhecimento das crianças na condição de cidadãs. A sensibilidade dos órgãos competentes, da política, da escola e do compromisso com a justiça social favoreceu o engajamento na construção de uma sociedade democrática de direitos para suprir as necessidades delas, pois tais práticas de construção democráticas vão favorecer para que, também, os órgãos de instâncias maiores levem em conta as premências das populações infantis, em especial as das classes menos favorecidas e expropriadas ao longo da nossa história. Diante de tais acontecimentos, se poderá, com a LDB e na revisão constitucional, contribuir para que os direitos da infância no Brasil se tornem reais ou, pelo menos, possíveis.

Contudo, é importante salientar que o fato de reconhecermos a importância da oferta educacional a todas as crianças de até 7 anos não garantirá mudanças estruturais nas suas condições de vida. Assim, se por um lado uma educação democrática considera a criança como ser social que faz parte de direitos que devem ser assegurados, por outro essa visão não pode ser enfraquecida por uma visão de assistencialismo e, portanto, por um paternalismo que mitifique os poderes da educação, colocando-os como panacéia para todos os males de uma sociedade marcada pelas desigualdades sociais.

Diante de fatos acontecidos no interior do Grupo Escolar João Pinheiro, fica evidenciada a necessidade de estabelecer diretrizes educacionais mais coerentes com suas práticas pedagógicas. Nesse sentido, para que as crianças do referido grupo tivessem um ambiente mais acolhedor a suas reais necessidades de desenvolvimento cognitivo, físico e emocional, as professoras e a diretora América, naquele período, já procuravam manter a organização da instituição, pois as condições de infra-estrutura do prédio eram precárias. Segundo depoimento da diretora:

O Grupo Escolar João Pinheiro estava muito acabado nos anos de 66, 68. Eu fiz muitas campanhas para arrecadar dinheiro para dar uma reforma no prédio, em tudo mesmo. As meninas - coitadas - carregavam água na lata para lavar essas coisas. Ah! Era um mau cheiro, uma coisa horrorosa, aí eu comprei uma mangueira, coloquei em um lugar que dava para arrumar o grupo todo, sem precisar carregar mais água na lata. Fiz também rifas e com o dinheiro ajudava manter o que o grupo precisava. Os professores tinham um bom relacionamento com todos, tinham prestígio na sociedade, mas - coitados - ganhavam mal. (CARVALHO, 2007).

A escola tinha preocupação com a limpeza externa de suas dependências, pois como nos apresenta Carvalho - todo sábado era dia de realizar aquela limpeza: vinha determinado da Delegacia de Ensino que as responsáveis pela faxina das escolas se reunissem em todo o Estado de Minas Gerais para organizar as salas de aula, mantendo seu mobiliário organizado, os edifícios sempre conservados, para receber bem as crianças. Portanto, a necessidade de higienização do grupo era constante entre elas. Porém, mesmo com o discurso de escolas bem equipadas pelo governo, o grupo escolar enfrentava em seu interior diversidades constantes, tendo muitas vezes que dispor de recursos humanos para enfrentar as falhas existentes na escola. Com isso, as crianças que frequentavam essa instituição lentamente conquistavam seu espaço de vivência, mesmo com todo rigor das disciplinas e autoridades impostas a elas dentro do grupo escolar. 
Já a portaria 66/69, de 28 de janeiro de 1970, que dispõe sobre a matrícula e o horário de funcionamento das aulas nas unidades de ensino elementar, supletivo, $5^{\mathrm{a}}$ e $6^{\mathrm{a}}$ séries primárias (curso complementar) e ensino emendativo, em 1970, e dá outras providências.

6. Serão admitidos à matrícula nos estabelecimentos de ensino (jardim de infância: Cursos Pré-primário, Primário supletivo, $5^{\mathrm{a}}$ e $6^{\mathrm{a}}$ e sexta séries e Ensino Emendativo) candidatos que comprovem a idade exigida nas diversas categorias de ensino através da certidão de registro civil. Os cartórios de registro civil expedirão, gratuitamente, certidão de nascimento, para efeito escolar, na forma da lei.

6.1. Consideram-se como tendo, na época da matrícula, 4 (quatro), 5 (cinco), 6 (seis), 7 (sete) e 11 (onze) anos e 14 (quatorze) anos, os candidatos que os completarem até 30 de abril de 1970.

Secretaria de Estado da Educação, em Belo Horizonte, aos 7 de novembro de 1969.

Resolução n. 51/70, do Regime Escolar, Capítulo I, do ano letivo:

Artigo $1^{\circ}$. O ano letivo terá duração mínima de 200 dias.

Artigo $2^{\circ}$. O dia letivo terá duração mínima de:

I Nos turnos diurnos 4 (quatro) horas e 30 (trinta) minutos, de modo a perfazer 800 (oitocentas) horas/aula anuais;

II No turno noturno 3 (três) horas;

III Nos cursos complementares 6 (seis) horas diárias.

Artigo 29 - Serão admitidas à matrícula, nos estabelecimentos e ensino elementar, as crianças em idade de 7 a 14 anos, observada a escala de prioridade que se refere o artigo 24 desta Resolução, quando o número de vagas não for suficiente para o atendimento destes alunos, além de atendimento a zoneamento, como requisito primeiro de matrícula.

Parágrafo único - Os candidatos à $1^{\mathrm{a}}$ série, serão matriculados de acordo com a seguinte ordem preferencial;

I - Alunos mais distantes da idade cronológica própria de série;

II - Alunos que, pela primeira vez, se candidatarem à matrícula, com a idade exigida pelo artigo 15 .

Artigo 15 - Para efeito do artigo 14, consideram-se como tendo quatro (4), cinco (5), seis (6), sete (7), onze (11) e 14 (quatorze) anos os candidatos que o completarem dentro de 90 dias do início das aulas.

Artigo 30 - Os alunos que hajam concluído o terceiro período do jardim de infância ou o curso ministrado em classes pré-primárias, anexas às unidades de ensino primário elementar, terão assegurada a matrícula na $1^{\text {a }}$ série do Curso Primário das mesmas unidades. (Belo Horizonte, 9 de novembro 1970).

Em relação aos horários de aulas, o quadro III, apresenta como foram organizadas atividades letivas. 


\section{QUADRO III}

Horário de aula do Grupo Escolar João Pinheiro e Grupo Escolar Mascarenhas ${ }^{4}$ GRUPO ESCOLAR JOÃO PINHEIRO GRUPO ESCOLAR MASCARENHAS

\begin{tabular}{|c|c|c|c|cc|}
\hline Entrada & Saída & Séries & Entrada & Saída & Séries \\
\hline $\mathbf{7 h}$ & $10 \mathrm{~h} 30$ & $3^{\mathrm{a}}$ e $4^{\mathbf{a}}$ & & & \\
\hline \hline $\mathbf{1 0 h 3 0}$ & $\mathbf{1 4 h}$ & $\mathbf{1}^{\mathbf{a}} \mathbf{e} \mathbf{2}^{\mathbf{a}}$ & $\mathbf{1 4 h}$ & $\mathbf{1 7 h 3 0}$ & $\mathbf{1}^{\mathbf{a}} \mathbf{a}^{\mathbf{a}}$ séries \\
\hline
\end{tabular}

FONTE: ESCOLA ESTADUAL JOÃO PINHEIRO.

No ano de 1972 assume a direção da escolar a professora Neiva Marilla de Oliveira Laterza, que atuou como diretora efetiva de 1972 a 1989. De acordo com depoimentos feitos por ela, o seu ingresso na vida escolar se deu de maneira bastante consciente, pois gostava muito de crianças e de trabalhar com elas. Essa vontade foi crescendo e resolveu, portanto, fazer o ginásio para ter uma formação melhor. Estudou, naquela época, no colégio particular São José, ${ }^{5}$ depois foi estudar em outro colégio, o Santa Martelina, em São Paulo, onde fez o curso Normal. Atuou durante uma época como professora na Escola João Pinheiro, e teve o seu ingresso através do concurso realizado naquele período. Tendo uma boa classificação, pôde escolher seu local de trabalho, já que residia nas proximidades da escola. Fez sua opção para atuar como professora naquele estabelecimento, que no momento exigia de seu professores bastante compromisso com seus trabalhos pedagógicos, tinham bastante rigor em seus assuntos educacionais. Portanto, no intervalo entre ser professora, já estava atuando como vice-diretora naquele momento, quando recebeu o convite para assumir a direção da escola.

Sobre sua escolha Laterza diz:

Assumi a direção do Grupo João Pinheiro a pedido do delegado de Ensino José Maria Fenelon, pois naquele momento estava na vicedireção, já tinha saído da regência da sala de aula. Fiquei muito preocupada com o convite, pois era muito nova ainda não tinha experiência para ser diretora. Fui a Uberlândia, pois a delegacia naquela época era lá, fui conversar com ele porque fiquei com receio de assumir o cargo. Ele então pediu para assumir, pois não via outra pessoa com qualidades melhores para tal cargo. Disse que a escola enfrentava situações difíceis no momento que exigiam a minha permanência. $\mathrm{O}$ grupo estava perdendo muitos meninos, saindo para ir para outro lugar, conflitos entre professores, então tínhamos que solucionar essas dificuldades, dentre outras. Falei que só ficaria então até dezembro, isso era $1^{\circ}$ de julho, portanto ficaria só cinco meses para ajudar a resolver tais conflitos. Ele então concordou. (LATERZA, 2007).

Nesse intervalo, entre julho a dezembro do referente ano, a situação da escola apresentava melhoras, a presença dos pais em acontecimentos sociais já era frequente, as professoras estavam em um clima de harmonia, as crianças apresentavam melhoras em aspectos pedagógicos, e a frequência tinha aumentado bastante, relata Laterza. Então, ainda funcionava junto ao Grupo João Pinheiro o Grupo Escolar Mascarenhas que atendia crianças de 7 a 14 anos nas séries iniciais também. E tinha então que adequar os horários para atender as duas escolas, então os horários tinham que ser diferenciados, ficando estabelecidos como mostra o quadro III.

Porém, a Secretaria de Estado da Educação tinha horários estabelecidos para os ensinos, segundo a portaria 66/69, 28 de janeiro de 1970, que dispõe sobre a matrícula e o horário de funcionamento das aulas nas unidades de ensino pré-primário, primário 
elementar, supletivo, $5^{\mathrm{a}}$ a $6^{\mathrm{a}}$ séries primárias (curso complementar) e ensino emendativo, em 1970, e dá outras providências (retificação):

\section{Horário Escolar.}

41. As unidades escolares obedecerão ao seguinte, horário, conforme o número de turnos em que funcionarem:

41.1 Turno Único - De 12 (doze) a 16 (dezesseis) horas e 30 (trinta) minutos.

41.2 Dois turnos de 7 (sete) a 11 (onze) horas e 30 (trinta) minutos e de 12 (doze) a 16 (dezesseis) horas e 30 (trinta) minutos.

41.3 Três turnos - de 7 (sete) as 10 (dez) horas e 30 (trinta) minutos; de 11 (onze) ás 14 (quatorze) horas e 15 (quinze) minutos as 17 (dezessete) horas e 30 (trinta) minutos.

41.4: O curso Supletivo funcionará de 18 (dezoito) horas e 30 (trinta) minutos a 21 (vinte e uma) horas e 30 minutos.

41.5 As classes de ensino emendativo obedecerão ao regime de funcionamento dos grupos escolares ou da instituição mantenedora.

41.6 A duração das aulas do Curso complementar será de seis horas diárias; inclusive os períodos de merenda e recreação, cabendo à direção da escola estabelecer o horário de início e término das atividades escolares.

44. Decorrida a metade do dia letivo, nos estabelecimentos que funcionarem em dois turnos, haverá meia hora de intervalo, destinado à merenda e ao recreio.

44.1 - O intervalo destinado ao recreio será reduzido a 15 minutos em regime de três turnos.

Registre-se, publique-se, e cumpra-se. (GRUPO ESCOLAR JOÃO PINHEIRO, s. d, s. p.).

A situação que a escola vivenciava naquele momento - dividir suas dependências com outro grupo - muitas vezes criava conflitos internos com pais e os professores, pois as famílias queriam, de toda maneira, que seus filhos estudassem no grupo considerado pela comunidade como celeiro educacional, mesmo ao estudar em outro grupo com uma boa qualidade nas mesmas dependências. Os profissionais ficavam a todo o momento dando explicações de tal situação e tentando contornar as dificuldades encontradas para mostrar a importância, também, do outro grupo. De forma incipiente, explicavam que o método utilizado nos grupos tinha como finalidade ensinar seus filhos, alfabetizar, pois alfabetizar era uma necessidade social que ia muito mais que ensinar a codificar e decodificar palavras e que os dois estabelecimentos tinham essa preocupação.

Portanto, são tantas mães que esperavam da escola que seus filhos aprendessem a ler, escrever e a contar "para que não ficassem burros". Contudo, muitas achavam que a aprendizagem da leitura e da escrita requer ensino e deveria fazer parte do cotidiano da criança, mais especificamente no primário, como era estabelecido naquele momento, e tinham medo de seus filhos estarem sendo prejudicados. Diante dessa situação, o Grupo Escolar Mascarenhas não permaneceu por muito tempo como anexo da Escola João Pinheiro, pois os pais compreenderam a importância do grupo, que teve suas matrículas ampliadas e, portanto, mudou-se para outro local mais apropriado. 


\section{CONSIDERAÇÕES FINAIS.}

Vale a pena ressaltar que uma instituição escolar está inserida no local mediada pelos discursos político, religioso, econômico e ideológico, que são condicionadores do cotidiano escolar evidenciado na instauração de uma nova ordem social. Nessa perspectiva, embora sendo uma escola pública e laica, ela foi um veículo propagador de ensinamentos, tanto através de suas práticas cotidianas quanto de concepções transmitidas aos alunos através de conhecimentos, informações e condutas, incorporadas aos comportamentos sociais e políticos considerados com desejáveis para a época de ditadura militar.

É importante lembrar ainda que a Escola Estadual João Pinheiro foi um espaço que articulou muitas as atividades em seu cotidiano, em que algumas observações merecem ser sublinhadas: as práticas voltadas para o ensinamento dos rituais de religião, cânticos e orações voltadas para "Nossa Senhora", que aconteciam de forma "religiosa" todos os dias durante a entrada e saída da escola, bem como em alguns momentos era reforçadas no interior das próprias salas de aula. Presente também no contexto educacional valores como a ordem e a civilidade, ensinados em razão do período ditatorial. Esses ensinamentos eram realizados através da disciplina e da polidez; o civismo e o nacionalismo eram praticados através do culto aos símbolos pátrios: hinos, bandeira e heróis nacionais - o Hino Nacional deveria ser cantado obrigatoriamente na entrada da escola, pois a escola deveria seguir a determinação da Secretaria Estadual de Educação de Minas Gerais.

Ainda há a constante preocupação com a higienização, percebida nas referências feitas pelas professoras quanto ao material escolar. A disciplina imposta pelos professores, também, era outra característica presente em todos os ensinamentos. Percebe-se tal procedimento no depoimento da entrevistada Nascimento: Naquele momento, até o sinal fazia parte da rotina da escola: tinha horário correto, não atrasava nem adiantava um minuto; tanto para os professores quanto para os alunos (LATERZA, 2007), pois a escola tinha como proposta de trabalho em seu contexto educacional a prática de ensinamentos voltados para postura tradicional.

Quanto ao fato de se trabalhar com tal procedimento didático e práticas pedagógicas, sobressaía no contexto apresentado a grande significação atribuída à postura que os alunos deveriam fazer a leitura em voz alta, pois a pronúncia das palavras deveria ser observada atentamente pelos mestres.

O verbo e a tabuada tinham que ser cantados, isto é, meramente memorizados, sem significado para o desenvolvimento dos alunos da educação infantil. As crianças das séries iniciais trabalhavam no período da alfabetização mais especificadamente com a cartilha da Infância; o método desenvolvido nos trabalhos dos professores era o global analítico, pois - como define Rizzo (1983) - partia-se do todo para as partes. Assim, nas salas de aula também se seguia um padrão, ou seja, um ritual estabelecido para que os alunos conduzidos pelos ensinamentos transmitidos incorporassem os conteúdos apresentados, muitas vezes impostos para que fossem memorizados, aprendidos.

Havia certa rigidez disciplinar, que era apresentada pelos dirigentes e pelos professores aos alunos. Mas, de maneira geral, os métodos usados pelos professores, pelo diretor e pelos demais responsáveis pela educação na escola eram considerados como adequados, tanto pelos pais das crianças que frequentavam a escola como pelos professores que ali trabalhavam e pelos inspetores e profissionais dos órgãos responsáveis pela educação. Isso permite considerar que era intenção relacionar tais práticas no âmbito geral do período imposto pela ditadura militar.

Em síntese, em um primeiro momento da análise, considera-se que o conhecimento da história da infância — ou seja, da criança no seu meio mais amplo, o contexto social ajuda a identificar o processo educativo ao longo da "história da criança", mas colocando-a 
em seus respectivos contextos, ou seja, nas diversas realidades a que foi submetida e, em particular, na chamada "modernidade pedagógica", a qual trouxe consigo a "necessidade" de regras que assegurassem a convivência com o grupo.

Nesse cenário, foi possível traçar algumas dimensões da infância diante de tal realidade vivenciada no interior da Escola Estadual João Pinheiro, por ser a criança aluno de uma instituição pública, há que ser consideradas as dimensões constituídas pelas regras transmitidas a este aluno. Também são importantes as normas criadas pelos professores, bem como as impostas pela sociedade, sobretudo, as definidas pelo Estado Militar entre 1964 a 1985, pois elas evidenciam normas e práticas articuladas com objetivos que variavam de acordo com os interesses dessa época, utilizando métodos, processos e dispositivos estabelecidos pela concepção pedagógica que esposada no período militar: o tecnicismo. Os mecanismos utilizados pelos mestres na escola são alguns exemplos que nos ofereceram pistas para percebermos como os ensinamentos da "educação tecnicista" naquele momento vinham sendo por eles apresentados aos alunos e como contribuíram para o desenvolvimento de tais práticas - muitas vezes constituídas de ações imbuídas de uma autoridade delegada pelo estado e consubstanciada pela escola. Além de incorporarem influências de todos os segmentos possíveis, assumiam uma vigilância disciplinadora e formadora de bons hábitos e boas atitudes, tão caros ao "estado de exceção" vigente no País durante 21 anos.

\section{Referências.}

CUnha, Luiz A.; GÓES, Moacyr. O golpe na educação. 11. ed. Rio de Janeiro: Jorge Zahar, 2002.

DREIFUSS, René A. 1964: a conquista do Estado. Petrópolis: Vozes, 1981.

FERREIRA, Marieta de Moraes (Org.). João Goulart: entre a memória e a história. Rio de Janeiro: FGV, 2006.

FREITAS, Marcos César \& BICCAS, Maurilane de Souza. História Social da Educação no Brasil (1926-1996). São Paulo: Cortez, 2009.

GERMAno, José W. Estado militar e educação no Brasil (1964-1985). 3. ed. São Paulo: Cortez, 2000.

KUHLMANn JR, Moysés. Educando a infância brasileira. In: LOPES, Eliane M. T.; FARIA FILHO, Luciano M.; VEIGA, Cynthia G. 500 anos de educação no Brasil. 3. ed. Belo Horizonte: Autêntica, 2003.

KUHLMANN JR, Moysés. Infância e educação infantil: uma abordagem história. Porto Alegre: Evangraf, 1998.

LOPes, Eliane M. T.; faria filho, Luciano M.; Veiga, Cynthia G. 500 anos de educação no Brasil. 3. ed. Belo Horizonte: Autêntica, 2003.

OLIVEIRA, Zilma R. Educação infantil: fundamentos e métodos. 2 ed. São Paulo: Cortez, 2005. 
RIzzo, Gilda. Os diversos métodos de ensino da leitura e da escrita: estudo comparativo. Papelaria América, 1983.

SKIDMORE, Thomas E. Brasil de Castelo e Tancredo 1964-1985. Rio de Janeiro: Paz e Terra, 1988.

SOUZA, Rosa de Fátima. História da Organização do Trabalho Escolar e do Currículo no Século XX (ensino primário e secundário no Brasil. São Paulo: Cortez, 2008.

SOUZA, Rosa de Fátima. In: SAVIANI, Dermeval. O legado educacional do século XX no Brasil. Campinas: Autores Associados, 2004.

FONTES.

CARVALHO, América C. Ituiutaba (MG), 29/3/2007. 1 fita cassete (60 minutos). Entrevista concedida a nós.

LAterza, Neiva M. L. O. Ituiutaba (MG), 12/1/2007. 1 fita cassete (60 minutos). Entrevista concedida a nós.

GRUPO ESCOLAR JOÃO PINHEIRO. Ata de promoção dos alunos e ata dos exames finais das classes de $1^{\mathrm{a}}$ a $4^{\mathrm{a}}$ séries.

GRUPO ESCOLAR JOÂO PINHEIRO. Cadernos de plano da professora Terezinha Gouveia Vasconcelos dos anos 1964, 1971, 1972, 1974.

GRUPO ESCOLAR JOÃo JoÂO PINHEIRO. Diário de classe de 1966 a 1988.

GRUPo escolar joÂo Pinheiro. Diário de Classe do ano de 1967-88.

escola estadual JoÂo pinheiro. Fichas de matriculas dos alunos 1976-1988.

eSCOla estadual joÂo Pinheiro. Livro de atas - livro de atas pedagógicas $1976-88$.

escola estadual joÂo pinheiro. Livro de atas - livro de termo de visita da supervisora de educação integrada - 1978-86.

ESCOLA eStadual JOÂO PINHEIRO. Livro de atas — em nome - 1979-88.

ESCOLA ESTADUAL JOÂO PINHEIRO. Livro de atas — em nome - 1982-88.

ESCOLA estadual JOÂO PINHEIRO. Livro de atas do colegiado - 1984-88.

ESCOLA ESTADUAL JOÃO PINHEIRO. Livro de ocorrência de professores, 29/9/1979.

ESCOLA MUNICIPAL DE $1^{\circ}$ E $2^{\circ}$ GRAU MACHADO DE ASSIS. Histórico, s. l., s.d.

GRUPo escolar Jõ̃o PINHeiro. Livro de recortes do Minas Gerais, 1962-1988.

GRUPO ESCOLAR JOÂO PINHEIRO. Registro geral de matricula do $\mathbf{1}^{\mathbf{0}}$ grau.

ituiutaba. Lei 106, de 24 de dezembro de 1908 - livro de leis da Comarca Municipal de Villa Platina/1908.

PARECER 990/72.

ITUIUTAB A. Decreto-lei n. 73. Ituiutaba, 25 de novembro de 1941. 
ITUiUtabA. Secretaria Municipal de Educação, Esporte e Lazer de Ituiutaba e Superintendência Regional de Ensino de Ituiutaba, 1985.

CIDADE DE ITUIUTAB A. Ituiutaba, ano I, n. 4, 1966.

CIDADE DE ITUIUTAB A. Ituiutaba, ano II, n. 90, 1967.

CIDADE DE ITUIUTAB A. Ituiutaba, ano II, n. 16, 1968.

CIDADE DE ITUIUTAB A. Ituiutaba, ano VII, n. 346, 1972.

CIDADE DE ITUIUTABA. Ituiutaba, ano VIII, n. 395, 1973.

CIDADE DE ITUIUTABA. ITUIUTABA, ANO XVI, N. 2.291, 1981.

CIDADE DE ITUIUTABA. ITUIUTABA, ANO XVI, 1983.

\section{Notas}

\footnotetext{
${ }^{1}$ Doutor em História pela Universidade de São Paulo (USP). Professor da Faculdade de Educação e do Programa de Pós-Graduação em Educação da Universidade Federal de Uberlândia (UFU).

${ }^{2}$ Doutora em Educação pela Universidade Federal de Uberlândia (UFU). Analista Educacional da Superintendência Regional de Ensino de Ituiutaba-MG. Professora da Secretaria Municipal de Educação, Esporte e Lazer de Ituiutaba.
}

${ }^{3}$ O presidente do Estado de Minas Gerais, Júlio Bueno Brandão, que, com o secretário Estevão Leite de Magalhães Pinto, criou em Villa Platina, pelo Decreto 2.327, o Grupo Escolar de Villa Platina, assinado por ambos, no dia 22 de dezembro de 1908, e publicado no "Minas Geraes" - Órgão Official dos "Poderes do Estado", no dia 23 de dezembro de 1908. Por este ato foi concretizado a criação do então "Grupo Escolar João Pinheiro", que recebeu este nome em homenagem ao presidente que procedeu à iniciativa de promover a reforma educacional em Minas, por meio da Lei no 439 de 28/09/1906.

${ }^{4}$ O Grupo Escolar Ildefonso Mascarenhas da Silva teve suas instalações inauguradas no dia 9 de março de 1947, sob a direção de Maria Moraes — esse foi o segundo grupo escolar do município; em 1954 funcionava junto ao então Grupo Escolar João Pinheiro.

${ }^{5}$ O Colégio São José foi fundado em 1940, pelos padres Estigmatinos José Tondim e Julio Sieef. Era popularmente chamado de Escola do Laurindo, pois atuava como professor naquele colégio o professor Laurindo, que ocupava importantes cargos na primitiva cidade (OLIVEIRA, 2003, p. 58).

Recebido em Janeiro/2014

Aprovado em Fevereiro/ 2014 